Research Article

\title{
Evaluation of the Adaptability of an EPB TBM to Tunnelling through Highly Variable Composite Strata
}

\author{
Tao Li $\mathbb{D}^{1}{ }^{1}$ Jinwu Zhan, ${ }^{2}$ Chao $\mathrm{Li}^{3}$ and Zhongsheng Tan ${ }^{1}$ \\ ${ }^{1}$ School of Civil Engineering, Beijing Jiaotong University, Beijing 100044, China \\ ${ }^{2}$ School of Civil Engineering, Fujian University of Technology, Fuzhou 350118, China \\ ${ }^{3}$ Shenzhen Urban Public Safety and Technology Institute, Shenzhen 518046, China \\ Correspondence should be addressed to Tao Li; taoli@bjtu.edu.cn
}

Received 3 March 2021; Revised 22 June 2021; Accepted 19 July 2021; Published 28 July 2021

Academic Editor: Abdul Qadeer Khan

Copyright (C) 2021 Tao Li et al. This is an open access article distributed under the Creative Commons Attribution License, which permits unrestricted use, distribution, and reproduction in any medium, provided the original work is properly cited.

\begin{abstract}
The adaptability of an earth pressure balance (EPB) tunnel boring machine (TBM) to complex geological strata needs to be evaluated when a tunnel project is set up. It is helpful for better design and more suitable technical parameters of the machine. Because the factors that influence adaptability are numerous and interrelated, their effects also differ; hence, a quantitative assessment of adaptability is generally difficult. In the present study, a method for quantitatively evaluating the excavation adaptability of an EPB TBM was developed using an analytic hierarchy process (AHP) and fuzzy comprehensive evaluation. The method first involves an initial selection of factors that may influence tunnelling. Based on the expert questionnaire and their influence weights determined by AHP, the 10 evaluation indexes from 25 primary indexes were selected to establish the evaluation index system (EIS) including a target, criteria, and index level. Fuzzy membership functions are then derived one after another based on the effect of each evaluation index on the EBP TBM tunnelling process. A fuzzy mathematical method was finally presented to determine the adaptability of an EPB TBM excavation performance. The proposed method was applied to two special sections of diameter $6.98 \mathrm{~m}$ excavated by two EPB TBMs in the Shenzhen Metro Line 11 project. The geological exploration shows that these two tunnel sections pass through typical composite strata in Shenzhen. The determined adaptability grades of the EPB TBMs used for composite strata were confirmed by the actual tunnel excavation. It indicates that the developed method is reasonable and useful to evaluate tunnelling adaptability of EPB TBM.
\end{abstract}

\section{Introduction}

Composite strata are often encountered when using the shield tunnelling method to construct subway tunnels in South China. Strata of this type are characterized by a complex and highly variable composition, with large differences occurring between the strengths of different sections. Researchers in China first encountered such strata during the tunnelling of Line 1 of the Guangzhou Metro. The unique geological conditions created enormous difficulties when using ordinary earth pressure balance (EPB) shield machines for tunnel excavation $[1,2]$. Composite EPB shield machines were first introduced to China to address this issue $[3,4]$. Such machines combine the advantages of hard-rock tunnel boring machines (TBMs) and soft-ground shield machines, and they are commonly referred to as EPB TBMs. Although these machines are now widely used in the region, composite strata continue to pose difficulties in tunnelling. This includes the need for frequent switching of boring modes, severe wear and tear of the cutterheads, and schedule overruns. In severe cases, the shield tunnelling method may have to be abandoned and replaced by the shallow tunnelling method [5]. There is thus an urgent need for a method for evaluating the tunnelling adaptability of an EPB TBM in composite strata. It could help to decide whether mechanical excavation should be adopted for such tunnel projects. The evaluation results would further determine the technical parameters of EPB TBM and even the tunnelling method.

There have been some research findings on the factors that affect EPB TBM excavation and the associated 
construction risks. For example, Zhao et al. [6] detailed the effects of composite strata on EPB TBM tunnelling based on a case study conducted on an actual engineering project. Tokgoz et al. [7] also analysed the relationship between the geotechnical and tunnelling parameters to evaluate the capability of an EPB TBM for tunnelling through fine-grained soil strata and examine the associated risks. Hu et al. [8] and Hyun et al. [9] used fault tree analysis and the analytic hierarchy process (AHP) to examine the risks of EPB TBM construction and proposed some targeted control measures. Hong et al. [10] used event tree analysis to evaluate the risks of underwater tunnelling using an EPB TBM. More studies have, however, been conducted on the boreability and performance of hard-rock TBMs and the influencing factors. Sapigni et al. [11] used geotechnical grading standards to evaluate the performance of a TBM, while Yan et al. [12] took energy consumption during the tunnelling process as a key indicator and analysed the construction efficiency of shield tunnelling through soft deposit. Mikaeil et al. [13] applied the multifactor fuzzy method to examine the hardrock boreability of a TBM. Lin et al. [14] proposed a novel fuzzy model for identifying high-risk factors during deep excavations in karst geological ground. Dudt and Delisio [15] used the penalty factor method to predict the performance of a TBM in highly variable strata. Furthermore, owing to the uncertainties of the various impact factors of TBM tunnelling, fuzzy mathematical methods have been widely used to predict the boreability of the machine [16-19]. Rostami [20] presented a comprehensive review and evaluation of existing models for predicting TBM's performance under difficult strata conditions and reported several new research findings. Bernados and Kaliampakos [21] introduced a vulnerability index for describing the uncertainties of the strata parameters and proposed a methodology for evaluating the probability of a geological disaster occurring during TBM tunnelling. Farrokh and Rostami [22] presented a detailed description of the impact of poor geological conditions on the performance of doubleshield TBMs based on the construction of the Ghomroud Tunnel in Iran. In a recent comprehensive report, Gong et al. [23] discussed the main issues encountered during TBM tunnelling under poor geological conditions and the corresponding mitigation measures. Considering the complexity of the relevant issues, mathematical methods applicable to multifactorial analysis are used to select the appropriate TBM and shield and assess the construction risks of a project. Such methods include AHP, decision analysis, and the use of expert systems [24-29]. Recently, artificial intelligence (AI) models and related methods have been applied to some issues in shield tunnelling, for example, predicting disc cutter life and modelling performance of EPB shield tunnelling [30-34].

It can thus be seen that many efforts have been devoted to determine the various factors affecting EPB TBM tunnelling and also to evaluate the EPB TBM's performance and the construction risks in difficult ground conditions. Nevertheless, there remains a lack of a method to quantitatively evaluate the tunnelling adaptability of EPB TBMs under complex geological conditions.
The aim of the present study was to develop a viable and quantitative method for evaluating the tunnelling adaptability of EPB TBMs in composite strata. The methodology for evaluation is first presented, which is based on AHP and fuzzy comprehensive evaluation (FCE). Secondly, the factors that affect the adaptability of an EPB TBM were then described according to the study and practice of EPB TBM in Shenzhen Metro construction. AHP was then used to determine the weights of these primary factors. Based on the expert questionnaire and their influence weights determined by AHP, the evaluation indexes were selected to form the evaluation index system (EIS) comprising the target, criteria, and index layers. Fuzzy membership functions were then derived one after another based on the effect of each evaluation index on the EBP TBM tunnelling process. Thirdly, a fuzzy mathematical method was presented to determine the adaptability of an EPB TBM excavation performance. Finally, the proposed method was verified by applying it to two special sections passing through composite strata of the Shenzhen Metro Line 11. These sections were excavated using the EBP TBPs with a diameter of $6.98 \mathrm{~m}$, which were applied for the first time in Shenzhen Metro construction.

\section{Methodology for Evaluating Adaptability}

For an EPB TBM, tunnelling adaptability refers to the ability of the machine to adapt to the various factors that affect tunnel excavation. This ensures that the machine can manifest its design effectiveness to complete the tunnelling task.

\subsection{Evaluation Indexes and Evaluation Index System.} Because the adaptability of an EPB TBM is affected by numerous factors, it was necessary to first select the most important or critical factors in the present study. Each shortlisted factor was then comprehensively described using a type of quantitative index. The evaluation indexes were selected based on considerations such as project implementation, results of scientific research, expert opinion, and mathematical assessment.

Based on the selected quantitative indexes, an evaluation index system (EIS) can be established so as to accurately reflect the impact of the various factors on tunnelling adaptability. Because influencing factors are not only often numerous but also interrelated, each evaluation index in an EIS should be highly representative when used to characterize the impact of a particular factor. Moreover, the principles of hierarchy, validity, and conciseness were needed to construct an EIS $[35,36]$.

\subsection{Fuzzy Membership Function of the Evaluation Indexes.} The evaluation indexes have different units, attributes, and degrees of importance, which causes a lack of commensurability among them. Hence, a fuzzy membership function (FMF) can be used to achieve commensurability among the indexes. The value of the function describes the relationship between an uncertain quantity $x$ and a membership function $v(x)$, which is defined in the interval $[0,1]$. The FMF may take different forms such as trigonometric, exponential, and 
Gaussian. To simplify the implementation of FMF, only a straight line and trapezoid were considered in this study.

2.3. Weights of the Evaluation Indexes. The weights of the different evaluation indexes were determined using AHP $[35,36]$. The process was as follows.

2.3.1. Hierarchy of Evaluation Indexes. After setting the evaluation targets, their mutual impact and membership relationships between the evaluation indexes were used as the bases for ranking them in descending order, with respect to the target, determined criteria, and index layers. The indexes at higher levels thus predominated over those at lower levels.

2.3.2. The Judgment Matrix. The relative importance of a pair of indexes can be qualitatively determined using the judgment matrix. For the comparison of evaluation indexes $U_{i}$ and $U_{j}(i, j=1, \ldots, n)$, Saaty [35] proposed the use of Table 1 for the assignment of values to $a_{i j}$ in the judgment matrix $\boldsymbol{A}$. A comparison of $U_{i}$ and $U_{j}$ defines $a_{i j}$, while that of $U_{j}$ and $U_{i}$ defines $a_{i j}=1 / a_{i j}$.

Although the judgment matrix $\mathbf{A}$ established using the above method may objectively reflect the different impacts between a pair of indexes, a certain degree of inconsistency is unavoidable when analysing the results of comparing all indexes. To address this problem, the elements of the matrix $\boldsymbol{A}$ should also satisfy the following equation:

$$
a_{i j} a_{j k}=a_{i k}, \quad \forall i, j, k=1,2,3, \ldots, n .
$$

2.3.3. Single Hierarchical Arrangement (SHA). For the matrix $\boldsymbol{A}$, it was assumed that $\boldsymbol{\Omega}\left(\omega_{i}\right)$ is the eigenvector corresponding to the maximum eigenvalue of $\lambda_{\max }$. After normalization, $\boldsymbol{\Omega}$ would represent the hierarchy of weights and the relative importance between the indexes on one level and a specific index on a higher level. The maximum eigenvalue of $\boldsymbol{A}$ and its corresponding eigenvector could be approximately determined using the root mean square method, as follows:

(a) The product of the elements in each row of the matrix $\boldsymbol{A}$ is obtained:

$$
\delta_{i}=\left(\prod_{j=1}^{n} a_{i j}\right)^{1 / n}, \quad(i=1,2, \ldots, n) .
$$

(b) $\delta_{i}$ is normalized before the eigenvector $\boldsymbol{\Omega}$ is calculated:

$$
\omega_{j}=\frac{\delta_{j}}{\sum_{k=1}^{n} \delta_{k}}, \quad(j=1,2, \cdots, n) .
$$

(c) The maximum eigenvalue $\lambda_{\max }$ of the matrix $\mathbf{A}$ is calculated. Because $\boldsymbol{A} \boldsymbol{\Omega}=\lambda_{\max } \boldsymbol{\Omega}$, then
TABle 1: Method for assigning values to elements $a_{i j}$ in the judgment matrix $A$.

\begin{tabular}{lc}
\hline Value assignment basis & $a_{i j}$ \\
\hline$U_{i}$ and $U_{j}$ are equally important & 1 \\
$U_{i}$ is slightly more important than $U_{j}$ & 3 \\
$U_{i}$ is obviously more important than $U_{j}$ & 5 \\
$U_{i}$ is definitely more important than $U_{j}$ & 7 \\
$U_{i}$ is extremely more important than $U_{j}$ & 9 \\
Intermediate judgment for the above pairs & $2,4,6$, and 8
\end{tabular}

$$
\sum_{j=1}^{n} a_{i j} \omega_{j}=\lambda_{\max } \omega_{j}, \quad(j=1,2, \ldots, n) .
$$

Hence,

$$
\lambda_{\max }=\frac{1}{n} \sum_{i=1}^{n} \frac{\sum_{j=1}^{n} a_{i j} \omega_{j}}{\omega_{i}} .
$$

The consistency testing of the SHA is conducted as follows:

(a) The consistency index CI can be calculated as follows:

$$
\mathrm{CI}=\frac{\lambda_{\max }-n}{n-1}
$$

(b) To determine the corresponding mean random consistency index RI, the random method is used to construct 500 sample matrices. Random numbers between 1 and 9 were chosen and their respective reciprocals were used to construct a positive reciprocal matrix. The following definition would apply:

$$
\mathrm{RI}=\frac{\bar{\lambda}_{\max }-n}{n-1},
$$

where $\bar{\lambda}_{\max }$ is the mean of the maximum eigenvalues of these matrices.

(c) Consistency check: the consistency ratio is defined as $\mathrm{CR}=\mathrm{CI} / \mathrm{RI}$. If $\mathrm{CR}<0.10$, then the matrix $\mathbf{A}$ meets the condition for consistency; otherwise, a revision is required.

\subsubsection{Total Hierarchical Arrangement (THA).} Determination of the THA of various indexes is based on the hierarchical weights, especially those at the lowest layer, with respect to the target layer. The weights of the THA could be obtained by summing the weights of the SHA from top to bottom.

For the index set $\boldsymbol{U}=\left\{U_{1}, U_{2}, \ldots, U_{m}\right\}$, its THA weights are denoted by $u_{1}, u_{2}, \ldots, u_{m}$, respectively. Assuming that the index set one layer below $\boldsymbol{U}$ is $\boldsymbol{V}=\left\{V_{1}, V_{2}, \ldots, V_{n}\right\}$, the SHA weights of the latter set with respect to $U_{j}$ would be $v_{1 j}, \ldots, v_{n j}$. Obviously, $v_{i j}=0$ when $V_{i}$ and $U_{j}$ are unrelated. The method illustrated in Table 2 can be used to calculate the weight of the indexes in $V$ with respect to the THA weights $v_{1}, v_{2}, \ldots, v_{n}$. 
TABLE 2: Method for calculating the THA weights of $V$.

\begin{tabular}{cccccc}
\hline $\boldsymbol{U} / \boldsymbol{V}$ & $U_{1}$ & $U_{2}$ & $\ldots$ & $U_{m}$ & THA weights for index set $\boldsymbol{V}$ \\
& $u_{1}$ & $u_{2}$ & $\ldots$ & $u_{\mathrm{m}}$ & \\
\hline$V_{1}$ & $v_{11}$ & $v_{12}$ & $\ldots$ & $v_{1 m}$ & $v_{1}=\sum_{j=1}^{m} v_{1 j} u_{j}$ \\
$V_{2}$ & $v_{21}$ & $v_{22}$ & $\ldots$ & $v_{2 m}$ & $v_{2}=\sum_{j=1}^{m} v_{2 j} u_{j}$ \\
$\vdots$ & $\vdots$ & $\vdots$ & $\vdots$ & $\vdots$ & $\vdots$ \\
$V_{n}$ & $v_{n 1}$ & $v_{n 2}$ & $\ldots$ & $v_{n m}$ & $v_{n}=\sum_{j=1}^{m} v_{n j} u_{j}$ \\
\hline
\end{tabular}

Even when all layers pass the consistency test for SHA, it is still possible for the nonuniformity of the various layers to accumulate during comprehensive analyses. To avoid this nonuniformity in the final judgment, a consistency check of the THA should be conducted as follows.

Regarding the paired comparative judgment matrices formed by the indexes in set $\boldsymbol{V}$ that are related to $U_{j}$, it is assumed that these have passed the consistency test at the SHA stage and that the corresponding $\mathrm{CI}_{j}$ and $\mathrm{RI}_{j}$ have been solved. The THA of $\boldsymbol{V}$ would thus be given by

$$
\mathrm{CR}=\frac{\sum_{j=1}^{n} \mathrm{CI}_{j} u_{j}}{\sum_{j=1}^{n} \mathrm{RI}_{j} u_{j}} .
$$

The THA results are considered consistent if $\mathrm{CR}<0.1$.

2.4. Fuzzy Comprehensive Evaluation Model. Assuming that $\boldsymbol{U}=\left\{U_{1}, U_{2}, \ldots, U_{m}\right\}$ is the set of evaluation indexes for the evaluation target set $\boldsymbol{O}=\left\{O_{1}, O_{2}, \ldots, O_{n}\right\}$, then the basic model for FCE would be

$$
D=\bar{U} \times R,
$$

or

$$
\left\{D_{1}, D_{2}, \ldots, D_{n}\right\}=\left\{u_{1}, u_{2}, \ldots, u_{m}\right\} \times\left[\begin{array}{cccc}
r_{11} & r_{12} & \cdots & r_{1 n} \\
r_{21} & r_{22} & \cdots & r_{2 n} \\
\vdots & \vdots & \ddots & \vdots \\
r_{m 1} & r_{m 2} & \cdots & r_{m n}
\end{array}\right],
$$

where $\mathbf{D}$ is the set of comprehensive judgment values for $\mathbf{O}$ and $D_{i}$ is the adaptability degree of the evaluation target $O_{i}$. When $0 \leq D_{i} \leq 1$, " 0 " indicates complete inadaptability, while " 1 " indicates complete adaptability. $\bar{U}$ is the set of THA weights for the evaluation index $\mathbf{U}$, where $u_{i} \geq 0$ and $\sum_{i=1}^{m} u_{i}=1$. $\mathbf{R}$ is the matrix for the degree of membership between $\mathbf{V}$ and $\mathbf{O}$. The adaptability evaluation of $O_{i}$ can be performed based on the numerical value of $D_{i}$ and in accordance with the classification criteria in Table 3 .

\section{Tunnel Construction for the Shenzhen Metro Line 11}

The Shenzhen Metro Line 11 starts from Futian Station and ends at Bitou Station, with a total length of $51.681 \mathrm{~km}$ and 17 stations. In all the tunnel sections of Line 11, only the Chegongmiao-Hongshuwan section (Section C-H) with a length of $5477.9 \mathrm{~m}$ and the Nanshan-Qianhaiwan section (Section N-Q) with a length of $3582.6 \mathrm{~m}$ were excavated using EPB TBMs of diameter $6.98 \mathrm{~m}$, while other sections were constructed with common shield machines of diameter $6.30 \mathrm{~m}$. The site location of these two sections is shown in Figure 1.

3.1. Geotechnical Investigation. To investigate the site geotechnical conditions of these two sections, geophysical method and boreholes were mainly used before tunnel construction. A seismic reflection survey was carried out to explore the thickness of the overburden layers and the subsurface structures along the tunnel alignment. A total number of 1,047 boreholes were drilled to provide the site information. The borehole spacing along the tunnel alignment is arranged as follows: $100-500 \mathrm{~m}$ for a simple site, 30-50 $\mathrm{m}$ for a moderately complex site, and less than $30 \mathrm{~m}$ for a complex site. The physicomechanical parameters of the main stratum have been ascertained by geotechnical tests in laboratory.

The geological cross-sections of these two sections are shown in Figures 2 and 3, respectively. The profile gives an overall image of the ground condition along the tunnel alignment. The main strata and stratigraphic distribution traversed by this tunnel section are detailed in Figure 4 . The different types of strata and complex geological conditions are typical of composite strata. Some basic strength parameters of soil and rock samples are given in Table 4, which were obtained from laboratory tests such as direct and triaxial shear test. It can be seen that a large proportion of the strata comprises weathered granite strata, which is characterized by substantial strength variation.

The investigation report recognized that varied ground conditions and transitions from high strength granite to low strength weathered materials (and vice versa) would be a major challenge to EPB TBM tunnelling. The poor geological conditions encountered in Section C-H and Section N-Q during the tunnelling caused several difficulties (see Table 5).

3.2. Basic Functions of an EPB TBM. The EBP TBM of diameter $6.98 \mathrm{~m}$ used for tunnelling was manufactured by China Railway Engineering Equipment Group Co., Ltd. And first used in Shenzhen subway construction. Targeted designs are incorporated into a composite EPB TBM for overcoming the difficulties encountered during tunnelling through composite strata. The basic functions of the machine and the specifications of its cutterheads are detailed in Tables 6 and 7, respectively.

\section{Evaluation Indexes and Fuzzy Membership Functions for EPB TBM Tunnelling}

\subsection{Evaluation Indexes and EIS}

4.1.1. Preliminary Selection of Evaluation Indexes. The factors that affect EPB TBM tunnelling include the EPB TBM design, tunnelling method, geological conditions, and surrounding environment. A detailed analysis of the various influencing factors was conducted in this study, taking into account the geological and environmental conditions along the two aforementioned sections. Based on the study and 
TABLE 3: Adaptability classification for the evaluation targets.

\begin{tabular}{lcc}
\hline Grade & Description of adaptability & Degree of adaptability \\
\hline I & Completely adaptable & $\geq 0.9$ \\
II & Adaptable & $0.6-0.9$ \\
III & Slightly adaptable & $0.4-0.6$ \\
IV & Inadaptable & $0.1-0.4$ \\
V & Completely inadaptable & $\leq 0.1$ \\
\hline
\end{tabular}

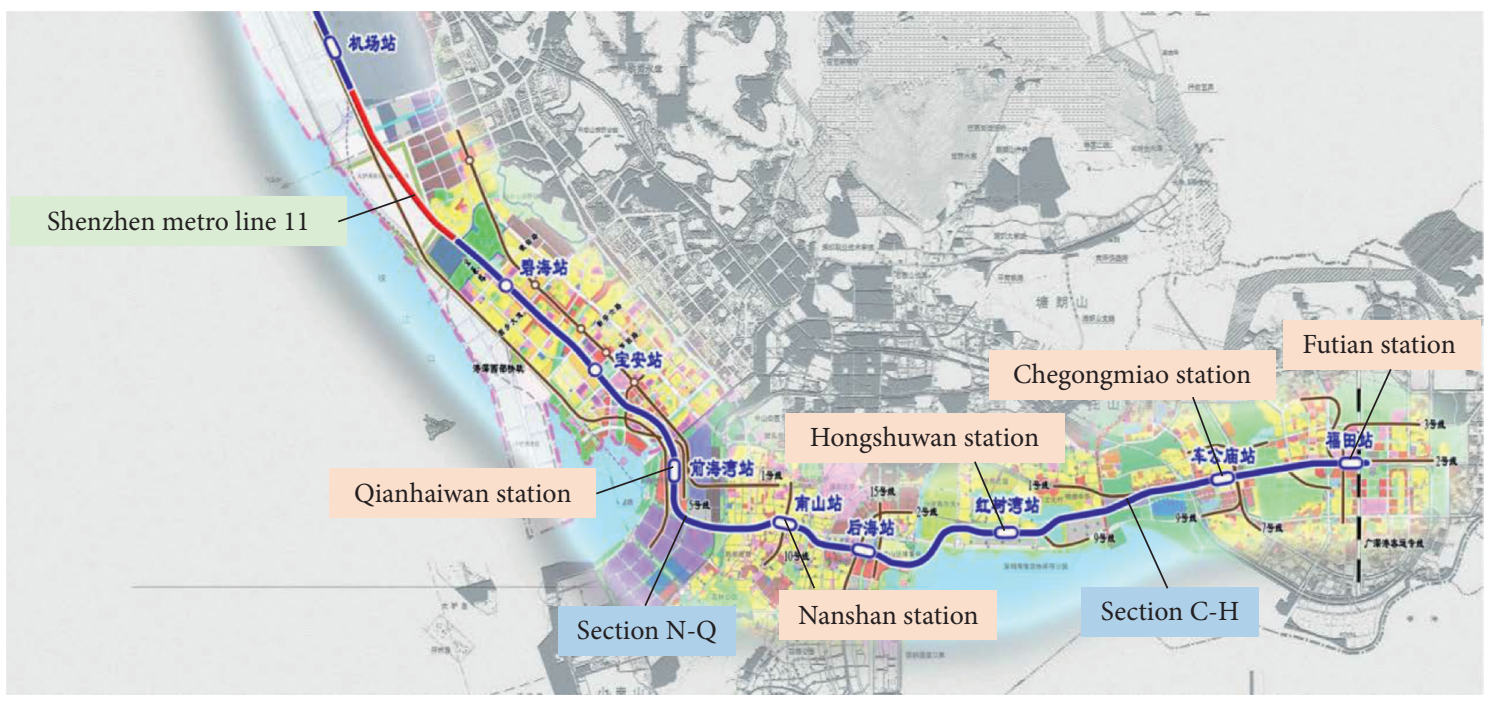

FIgUre 1: Site location map of Section C-H and Section N-Q.

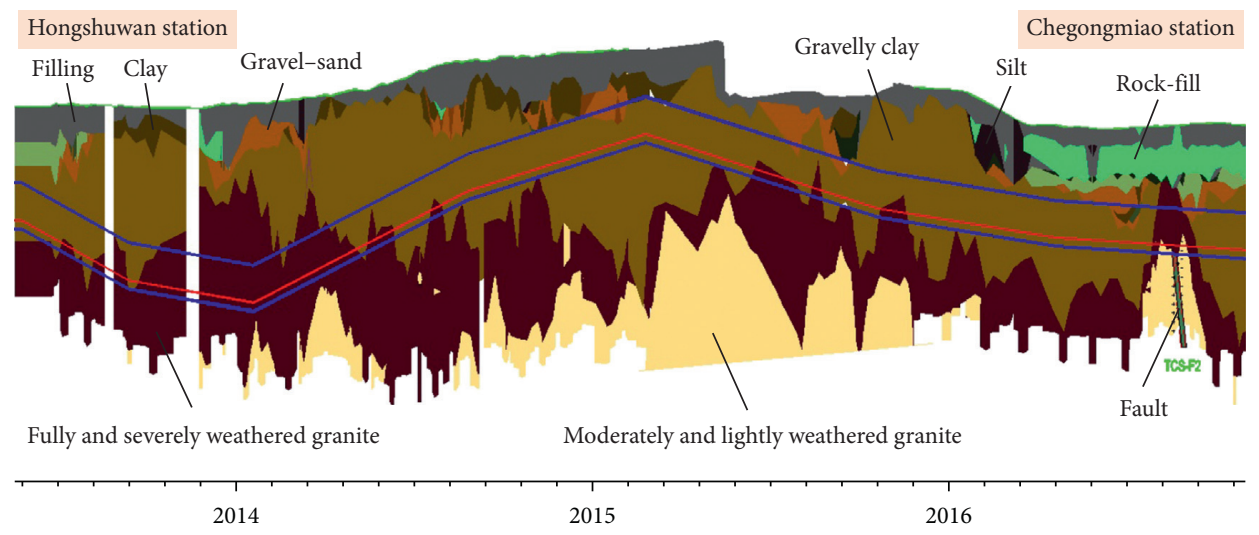

Figure 2: Geological profile of Section C-H of the Shenzhen Metro Line 11.

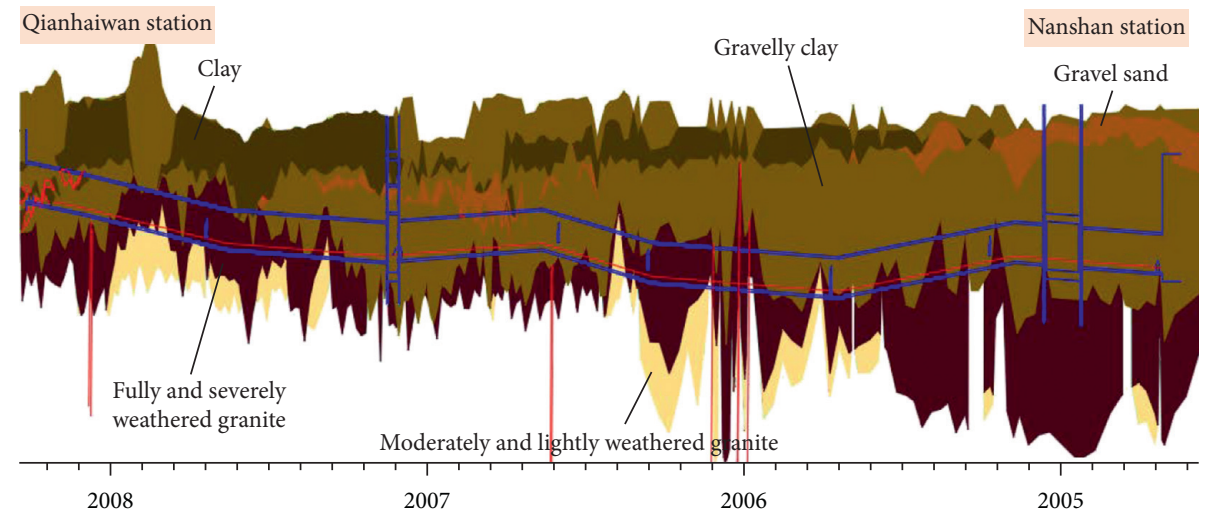

Figure 3: Geological profile of Section N-Q of the Shenzhen Metro Line 11. 


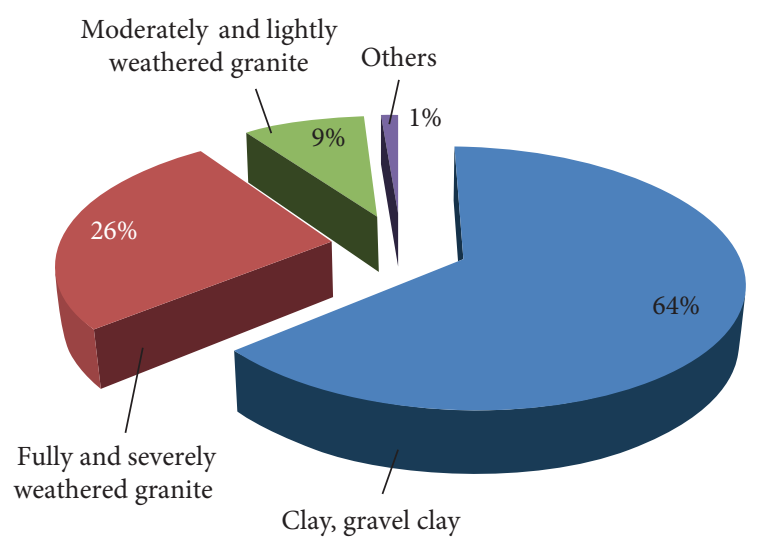

(a)

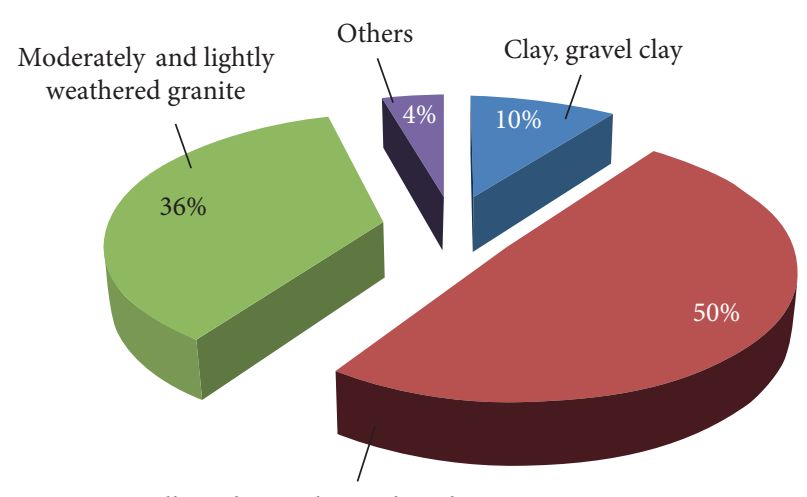

Fully and severely weathered granite

(b)

FIGURE 4: Distribution of main ground conditions along the tunnel alignment. (a) Section C-H. (b) Section N-Q.

TABLe 4: Physical and mechanical indexes of cored samples from tunnel site.

\begin{tabular}{lccc}
\hline Rock and soil type & Unit weight $\left(\mathrm{kN} / \mathrm{m}^{3}\right)$ & Cohesion $(\mathrm{kPa})$ & Inner friction angle (degree) \\
\hline Clay & $19.2-19.9$ & $20.0-25.0$ & $20.0-22.0$ \\
Gravel-sand & $20.0-20.4$ & & $32.0-35.0$ \\
Gravelly clay & $18.3-18.7$ & $24.0-25.0$ & $22.0-25.0$ \\
Fully weathered granite & $18.2-18.6$ & $28.0-30.0$ & $25.0-28.0$ \\
Severely weathered granite & $19.0-21.5$ & $38.0-40.0$ & $32.0-35.0$ \\
Moderately weathered granite & $25.1-25.5$ & & $45.0-60.0$ \\
Lightly weathered granite & $26.0-26.5$ & & $145.0-170.0$ \\
\hline
\end{tabular}

TABLe 5: Difficulties encountered during tunnel excavation of Section C-H and Section N-Q.

\begin{tabular}{|c|c|}
\hline Adverse geological conditions & Difficulties during tunnelling \\
\hline Silt and soft soil layer & Loss of stability at excavation surfac \\
\hline umulation layer & s and \\
\hline Clay layer & $\begin{array}{l}\text { Large stratigraphic disturbances; tendency for formation of mud cakes; augers tending to squirt } \\
\text { easily }\end{array}$ \\
\hline Mix ground & $\begin{array}{l}\text { Difficulty in controlling TBM attitude; poor adaptability of cutterheads and cutter bits to ground } \\
\text { conditions, necessitating frequent changing of construction method }\end{array}$ \\
\hline Laye & Severe wear and tear of cutterheads due to very strong rocks \\
\hline $\begin{array}{l}\text { Layer with spherical weathered } \\
\text { granite boulders }\end{array}$ & $\begin{array}{c}\text { Severe wear and tear of cutterheads and cutter bits due to very strong boulders, affecting the } \\
\text { progress of shield tunnelling }\end{array}$ \\
\hline Fract & e TBM attitude \\
\hline urated sand layer & High likelihood of water inrush and sand boiling; risk of excavation surface collapse \\
\hline
\end{tabular}

TABLE 6: Technical parameters of the EPB TBM.

\begin{tabular}{lcc}
\hline Parameter & Value & Unit \\
\hline Excavation diameter & 6,980 & $\mathrm{~mm}$ \\
Diameter of shield machine & $6,950 / 6,940 / 6,930$ & $\mathrm{~mm}$ \\
Rotation speed of cutterhead & $0-3.6($ inflection speed $=1.37)$ & $\mathrm{rev} / \mathrm{min}$ \\
Maximum advancing speed & 80 & $\mathrm{~mm} / \mathrm{min}$ \\
Maximum speed & 49,588 & $\mathrm{kN}$ \\
Main drive power & 1,120 & $\mathrm{~kW}$ \\
Rated torque & 7,806 & $\mathrm{kN} \cdot \mathrm{m}$ \\
Torque turnaround & 9,757 & $\mathrm{kN} \cdot \mathrm{m}$ \\
Screw conveyor (diameter/power/torque) & $900 / 315 / 210$ & $\mathrm{~mm} / \mathrm{kW} / \mathrm{kN} \cdot \mathrm{m}$ \\
\hline
\end{tabular}

practice of constructing Shenzhen Metro using shield tunnelling technology [5], 25 primary evaluation indexes $W_{1} \sim W_{25}$ were selected, as detailed in Table 8 .
To determine the mutual impacts of these indexes, 20 experts from universities, design institutes, and construction companies were asked to complete a 
TABLE 7: Specifications of the cutterhead and cutters.

\begin{tabular}{lc}
\hline Property & Specification \\
\hline Structural form & Hybrid (spokes + plate) \\
Opening ratio (central opening rate) & $33 \%(38 \%)$ \\
Cutterhead specifications (diameter $\times$ length) & $6,980 \mathrm{~mm} \times 1,635 \mathrm{~mm}$ \\
17-inch center hob (number/height/spacing) & $6 / 175 \mathrm{~mm} / 90 \mathrm{~mm}$ \\
17-inch single-blade hob (number/height/spacing) & $38 / 175 \mathrm{~mm} / 75-85 \mathrm{~mm}$ \\
Side scraper (number/height) & $12 / 135 \mathrm{~mm}$ \\
Scraper (number/height/width) & $49 / 135 \mathrm{~mm} / 250 \mathrm{~mm}$ \\
\hline
\end{tabular}

TABLE 8: Primary evaluation indexes for the adaptability of an EPB TBM during tunnelling.

\begin{tabular}{|c|c|c|c|c|}
\hline \multirow{2}{*}{$\begin{array}{l}\begin{array}{l}\text { Target } \\
\text { layer }\end{array} \\
\text { Criteria } \\
\text { layer }\end{array}$} & \multicolumn{4}{|c|}{ Adaptability degree of EPB TBM under mixed ground conditions $D$} \\
\hline & EPB TBM design $U_{1}$ & Tunnelling method $U_{2}$ & Geological conditions $U_{3}$ & Environment conditions $U_{4}$ \\
\hline Index layer & $\begin{array}{c}\text { Total thrust } W_{1} \\
\text { Cutterhead structure } W_{2} \\
\text { Cutterhead torque } W_{3} \\
\text { Cutterhead opening ratio } \\
W_{4} \\
\text { Muck improvement } \\
\text { technique } W_{5} \\
\text { Selection and layout of } \\
\text { cutters } W_{6} \\
\text { Cutter spacing } W_{7} \\
\text { Muck amount of screw } \\
\text { conveyor } W_{8}\end{array}$ & $\begin{array}{c}\text { Advancing speed } W_{9} \\
\text { Rotating speed of cutterhead } \\
W_{10} \\
\text { Earth pressure in cutterhead } \\
\text { chamber } W_{11} \\
\text { Shield tail void } W_{12} \\
\text { Wall-back grouting pressure } \\
W_{13}\end{array}$ & $\begin{array}{c}\text { Artificial fill } W_{14} \\
\text { Soft soil stratum } W_{15} \\
\text { Liquefied sand layer } W_{16} \\
\text { Residual soil layer } W_{17} \\
\text { Composite strata } W_{18} \\
\text { Microweathered granite } \\
\text { protrusions } W_{19} \\
\text { Hard-rock layer } W_{20} \\
\text { Fault crushed zone } W_{21} \\
\text { Spherical weathered boulders } \\
W_{22}\end{array}$ & $\begin{array}{c}\text { Underground structures } \\
W_{23} \\
\text { Ground buildings } W_{24} \\
\text { Structure of existing tunnel } \\
\text { lines } W_{25}\end{array}$ \\
\hline
\end{tabular}

questionnaire survey. Based on their judgments, values were first assigned to the judgment matrix as shown in Table 1. AHP was then used to analyse the weights and hierarchy of the indexes in each layer. Based on the analysis of weights and hierarchy, the 25 primary indexes were evaluated and reduced to 10 indexes that have strong influencing weights.

4.1.2. Evaluation Index System. As shown in Table 9, the 10 remaining indexes marked with $V_{1} \sim V_{10}$ were used to form the EIS of EBP TBM according to the principles for establishing an EIS. The fuzzy membership function of these indexes and the way they are evaluated are given in the next section.

\subsection{Fuzzy Membership Function of Indexes in the EIS}

4.2.1. Total Thrust $V_{1}$. The equation commonly used to predict the total thrust of an EPB TBM is

$$
F=\frac{F_{s} \pi D_{e}^{2}}{4},
$$

where $F_{s}$ is an empirical coefficient with a value within $700-1,200 \mathrm{kN} / \mathrm{m}^{2}$ and $D_{e}$ is the excavation diameter [37]. Based on the known value of $D_{e}=6.980 \mathrm{~m}$, the adaptability range of the total thrust was determined to be $26,785-45,918 \mathrm{kN}$. According to these values, the FMF of the total thrust was established as expressed by equation (12).

$$
v_{1}(x)=\left\{\begin{array}{lr}
0, & x<26785, \\
\frac{x-26785}{45918-26785}, & 26785 \leq x<45918, \\
1, & x \geq 45918 .
\end{array}\right.
$$

4.2.2. Cutterhead Torque $V_{2}$. The empirical equation for calculating the cutterhead torque is

$$
T=\alpha D_{e}^{3}
$$

where $\alpha$ is the torque coefficient, which ranges within 15-23 [37]. For $D_{e}=6.980 \mathrm{~m}$, the adaptability range of the cutterhead torque was determined to be $5,101-7,821 \mathrm{kN} \cdot \mathrm{m}$. The corresponding FMF is as expressed by equation (14).

$$
v_{2}(x)=\left\{\begin{array}{lr}
0, & x<5101 \\
\frac{x-5101}{7821-5101}, & 5101 \leq x<7821 \\
1, & x \geq 7821
\end{array}\right.
$$

4.2.3. Cutterhead Opening Ratio $V_{3}$. The selection of the cutterhead opening ratio is related to the adaptability of the cutterhead to the soil layer. The ratio is defined as 
TABLE 9: EIS of the EPB TBM.

\begin{tabular}{|c|c|c|c|}
\hline Target layer & \multicolumn{3}{|c|}{ Adaptability of EPB TBM to tunnelling under mixed ground conditions $D$} \\
\hline $\begin{array}{l}\text { Criteria } \\
\text { layer }\end{array}$ & EPB TBM design $U_{1}$ & Tunnel construction $U_{2}$ & Geological conditions $U_{3}$ \\
\hline Index layer & $\begin{array}{c}\text { Total thrust } V_{1}(\mathrm{kN}) \\
\text { Cutterhead torque } V_{2}(\mathrm{kN} \bullet \mathrm{m}) \\
\text { Cutterhead opening ratio } V_{3}(\%) \\
\text { Muck amount of screw conveyor } V_{4} \\
\left(\mathrm{~m}^{3} / \mathrm{h}\right) \\
\text { Cutter spacing } V_{5}(\mathrm{~mm})\end{array}$ & $\begin{array}{l}\text { Earth pressure in cutterhead chamber } V_{6} \\
\text { (MPa) } \\
\text { Wall-back grouting pressure } V_{7}(\mathrm{kPa}) \\
\text { Shield tail void } V_{8}(\mathrm{~mm})\end{array}$ & $\begin{array}{c}\text { Composite strata } V_{9}(\%) \\
\text { Spherical weathered boulders } V_{10} \\
(\mathrm{~m})\end{array}$ \\
\hline
\end{tabular}

$$
\xi=\frac{A_{s}}{A_{r}}
$$

where $A_{s}$ and $A_{r}$ are the opening area and the full cutting area of the cutterhead, respectively. The various magnitudes of the correlation value $\xi$ between the EBP TBM tunnelling time and the soil layer [37] are detailed in Table 10.

It can be seen from Table 11 that there is an optimal adaptability range for the cutterhead opening ratio. The corresponding FMF is expressed by equation (16).

$$
v_{3}(x)=\left\{\begin{array}{lc}
0, & x<15 \%, \\
\frac{x-15 \%}{25 \%-15 \%}, & 15 \% \leq x<25 \%, \\
1, & 25 \% \leq x<35 \%, \\
\frac{45 \%-x}{45 \%-35 \%}, & x \geq 45 \% .45 \%, \\
0, &
\end{array}\right.
$$

4.2.4. Slagging Ability of the Screw Conveyor $V_{4}$. Theoretically, the maximum amount of soil cut by the cutters of an EPB TBM during continuous excavation is given by

$$
Q_{1}=\frac{v_{\max } \pi D_{e}^{2}}{4}
$$

where $v_{\max }$ is the maximum driving speed of the EPB TBM [37]. Based on the data in Table 7, $Q_{1}$ was determined to be $183.7 \mathrm{~m}^{3} / \mathrm{h}$. The slagging ability of the screw conveyor was thus determined to be given by

$$
Q_{2}=\left(\frac{d}{F_{z}}\right)^{2.5} K_{d} K_{\beta},
$$

where $d$ is the diameter of the screw, $K_{z}$ is the synthetic characteristic coefficient of the muck (0.049 is generally used), $K_{d}$ is the filling coefficient ( 0.32 is generally used), and $K_{\beta}$ is the inclination coefficient (0.65 is generally used). For $d=0.9 \mathrm{~m}, Q_{2}=300.7 \mathrm{~m}^{3} / \mathrm{h}$.

Because the mixing of bentonite slurry with the soil inside the chamber of the EPB TBM expands the muck
TABle 10: Correlation between the cutterhead opening ratio and the soil layer.

\begin{tabular}{lcc}
\hline $\begin{array}{l}\text { Geological } \\
\text { stratification }\end{array}$ & Soil layer & $\xi(\%)$ \\
\hline & Cohesive soil & $25-30$ \\
Diluvium & Sandy soil & $15-20$ \\
& Gravelly soil & $20-25$ \\
& Interbedding of soft and hard soil & $30-35$ \\
\hline \multirow{4}{*}{ Alluvium } & Cohesive soil & $20-25$ \\
& Sandy soil & $10-15$ \\
& Gravelly soil & $15-20$ \\
& Interbedding of soft and hard soil & $20-25$ \\
\hline
\end{tabular}

TABLE 11: Cutter spacing for different rock types.

\begin{tabular}{lc}
\hline Rock type & Cutter spacing $(\mathrm{mm})$ \\
\hline Limestone & $70-85$ \\
Granite & $50-85$ \\
Gneiss & $60-70$ \\
Sandstone & $70-85$ \\
Shale & $85-100$ \\
\hline
\end{tabular}

volume, the maximum amount of muck conveyed by the screw is given by

$$
Q_{\max }=K_{s} Q_{1},
$$

where $K_{s}$ is the expansion coefficient of the muck, with 2.1 being considered as the maximum value, based on which $Q_{\max }=385.8 \mathrm{~m}^{3} / \mathrm{h}$.

Using the above calculation results, the expression of the FMF of the slagging ability of the screw conveyor was derived as

$$
v_{4}(x)= \begin{cases}0, & x<300.7, \\ \frac{x-300.7}{385.8-300.7}, & 300.7 \leq x<385.8, \\ 1, & x \geq 385.8 .\end{cases}
$$

4.2.5. Cutter Spacing $V_{5}$. The layout of the cutter spacing is significantly determined by the strength of the rock being cut. The cutter spacing used for common rocks is presented in Table 11 [2]. 
Based on a consideration of the rock strata of the two tunnel sections and noting that the adaptability range of the cutter spacing should be $40-100 \mathrm{~mm}$, the corresponding FMF was derived as expressed by equation (21).

$$
v_{5}(x)= \begin{cases}0, & x<40, \\ \frac{x-40}{60-40}, & 40 \leq x<60, \\ 1, & 60 \leq x<80, \\ \frac{100-x}{100-80}, & 80 \leq x<100, \\ 0, & \end{cases}
$$

4.2.6. Earth Pressure in the Cutterhead Chamber $V_{6}$. During EPB TBM tunnelling, the maximum and minimum control pressures on the excavation surface are, respectively, given by [38].

$$
\begin{aligned}
& P_{\text {max }}=P_{w}+P_{0}+P_{i}, \\
& P_{\text {min }}=P_{w}+P_{a}+P_{i},
\end{aligned}
$$

where $P_{\mathrm{w}}$ is the groundwater pressure, $P_{0}$ is the static earth pressure, $P_{a}$ is the active earth pressure (for strata with differentially weathered granite, the loose pressure of the granite could be considered representative), and $P_{i}$ is the preparatory pressure for compensating for the loss in pressure during tunnelling $(0.01-0.02 \mathrm{MPa}$ is generally used).

Using the known maximum depth of the tunnelling section of $30.5 \mathrm{~m}$ and geotechnical data, $P_{\max }$ was determined to be $0.320 \mathrm{MPa}$; using Rankine's theory, $P_{a}$ was determined to be $0.170 \mathrm{MPa}$; and using Protodyakonov's theory, the loose pressure was determined to be $0.150 \mathrm{MPa}$. Based on these results, the FMF of the earth pressure in the cutterhead chamber was derived as expressed by equation (23). It should be noted that ground uplift due to excessive pressure was not considered.

$$
v_{6}(x)=\left\{\begin{array}{lc}
0, & x<0.15, \\
\frac{x-0.15}{0.32-0.15}, & 0.15 \leq x<0.32 \\
1, & x \geq 0.32 .
\end{array}\right.
$$

4.2.7. Grouting Pressure $V_{7}$. The grouting pressure is related to the earth and water pressures, segment strength, TBM type, and characteristics of the slurry material. It was observed during the construction of the Shenzhen Metro that the synchronous grouting pressure generally did not fall below $200 \mathrm{kPa}$ [5]. Hence, the maximum permissible grouting pressure [1] was determined to be given by

$$
P_{f}=p_{0}+(0.9 \ln \eta+0.73) q_{u},
$$

where $\eta=\left(D_{e}+2 H\right) / D_{e}, H$ is the buried depth, $p_{0}$ is the overburden pressure, and $q_{u}$ is the unconfined compressive strength of the soil. Using the geotechnical data of the shallowest tunnel profile in the tunnel sections, it was determined that $P_{f}=600 \mathrm{kPa}$. Based on this result, the adaptability range of the grouting pressure was determined to be $200-660 \mathrm{kPa}$. The corresponding FMF is expressed by equation (25).

$$
v_{7}(x)=\left\{\begin{array}{lc}
0, & x<200, \\
\frac{x-200}{660-200}, & 200 \leq x<660, \\
1, & x \geq 660 .
\end{array}\right.
$$

4.2.8. Shield Tail Void $V_{8}$. The selected amount of shield tail impacts its sealing effect and determines the soil deformation. Statistical data from actual cases of using different tail voids are presented in Table 12 [37].

Generally, the shield tail void should not be less than $30 \mathrm{~mm}$. In addition, based on observations from the construction of the Shenzhen Metro, the maximum void is approximately $65 \mathrm{~mm}$ [5]. Thus, the adaptability range for the void should be $30-65 \mathrm{~mm}$. The corresponding FMF is

$$
v_{8}(x)=\left\{\begin{array}{lc}
0, & x<30, \\
\frac{x-30}{65-30}, & 30 \leq x<65, \\
1, & x \geq 65 .
\end{array}\right.
$$

4.2.9. Composite Strata $V_{9}$. This refers to the occurrence of two or more strata with significantly different strengths on the excavation surface during tunnelling. Typical examples that were encountered in the two tunnel sections under consideration included strata containing differentially weathered granite, bedrock protrusions, and so on. The average uniaxial compressive strength of the rocks was $80 \mathrm{MPa}$, although the maximum strength could reach $135 \mathrm{MPa}$. This implies substantial strength variation over the different parts of the excavation surface. The existence of hard rocks within the composite strata clearly impacted the tunnelling negatively. The strata composition ratio is defined as

$$
R_{c}=\frac{H_{h}}{D_{e}}
$$

where $H_{h}$ is the thickness of the hard-rock layer at the excavation surface. 
TABLE 12: Case values of the shield tail void [37].

\begin{tabular}{lccc}
\hline & \multicolumn{3}{c}{$\begin{array}{c}\text { Number of constructed } \\
\text { tunnels }\end{array}$} \\
& $25 \mathrm{~mm}$ & $30 \mathrm{~mm}$ & $40 \mathrm{~mm}$ \\
\hline$<3$ & 93 & 7 & 0 \\
$3-5$ & 63 & 34 & 2 \\
$5-7$ & 89 & 11 & 0 \\
$>7$ & 25 & 25 & 50 \\
\hline
\end{tabular}

Based on the observations from tunnelling through composite strata during the construction of the Shenzhen Metro, when $R_{c}<15 \%$, the excavation surface may be treated as a homogeneous soil layer, which does not adversely affect EPB TBM tunnelling. However, when $R_{c}$ is $40 \%-60 \%$, the impact on shield tunnelling is the most severe. This includes partial loading of the main bearing, increased wear and tear of the cutter bits, and difficult tunnelling and attitude control [5]. The FMF of the composite strata was determined to be as expressed by equation (28).

$$
v_{9}(x)= \begin{cases}1, & x<30 \%, \\ \frac{35 \%-x}{35 \%-30 \%}, & 30 \% \leq x<35 \%, \\ 0, & 35 \% \leq x<60 \%, \\ \frac{x-60 \%}{65 \%-60 \%}, & x \geq 65 \% . \\ 1, & \end{cases}
$$

4.2.10. Spherical Weathered Boulders $V_{10}$. Spherical weathered boulders occur in various shapes, with their sizes ranging from tens of centimeters to several meters. Their uniaxial compressive strength is $80-200 \mathrm{MPa}$ and they mostly occur in strata comprising fully and severely weathered granite. Their random spatial distributions pose severe challenges to shield tunnelling. However, construction experience has shown that boulders smaller than $0.3 \mathrm{~m}$ minimally impact excavation. Conversely, those larger than 2 m easily jam the cutterhead, with a supplementary measure such as manual excavation or directional blasting required to continue the tunnelling. The FMF of spherical weathered boulders is

$$
v_{10}(x)= \begin{cases}1, & x<0.3, \\ \frac{2-x}{2-0.3}, & 0.3 \leq x<2.0, \\ 0, & x \geq 2.0 .\end{cases}
$$

4.3. Hierarchy of Evaluation Indexes. The hierarchy of the 10 evaluation indexes in Table 10 must be established before evaluating the adaptability of the EPB TBM shield tunnelling.

4.3.1. SHA. The experience gained from tunnelling through composite strata during the construction of the Shenzhen Metro was combined with existing research findings and expert opinion in assigning the judgment matrix values. This was done based on the relative importance of the evaluation indexes in the three layers. The weight of each index was then calculated before testing for consistency. The calculation results are presented in Tables 13 and 14 .

4.3.2. THA. The single hierarchies of the evaluation indexes in the three layers were used to obtain the THA weights using the method in Table 2 . The results are presented in Table 15.

\section{Evaluation of the Composite Strata Tunnelling Adaptability of an EPB TBM}

5.1. Assigning Values to the Evaluation Indexes. The values of $V_{1}-V_{5}$ are given in Table 7 . The values of $V_{6}-V_{8}$ were obtained using the test sections of length $200 \mathrm{~m}$, as presented in Table 16.

The distribution, rocks, and thicknesses of the composite strata in the two sections are given in Table 17. Because the impact of composite strata on shield tunnelling is related to the strata distribution range, the final value of $V_{9}$ should be the weighted average.

The geological exploration data indicated that spherical lightly weathered boulders occurred only in the right line of Section $\mathrm{C}-\mathrm{H}$. The sizes of the surveyed boulders range from 0.45 to $4.0 \mathrm{~m}$. As mentioned previously, boulders larger than $2 \mathrm{~m}$ are generally removed by other methods. Thus, the value of $V_{10}$ would be the highest value less than $2 \mathrm{~m}$.

The values assigned to the evaluation indexes using the above-described process are presented in Table 18.

5.2. Adaptability Evaluation. For the evaluation target set $\mathbf{O}=\left\{O_{1}, O_{2}, O_{3}, O_{4}\right\}$, it is assumed that $O_{1}$ and $O_{2}$ represent the tunnelling adaptabilities of the EPB TBM in the left and right lines of Section C-H, respectively, and $\mathrm{O}_{3}$ and $\mathrm{O}_{4}$ are the corresponding values for Section N-Q.

The set of the THA weights of the evaluation indexes $V$, denoted by $\bar{V}$, is presented in Table 19. Substituting the values of the different evaluation indexes in Table 18 into the corresponding FMFs in Section 4.2 would give the matrix $\mathbf{R}$ of the degree of membership of $\mathbf{V}$ in $\mathbf{O}$ as follows: 
TABLE 13: Weights of the evaluation indexes in the criteria layer.

\begin{tabular}{lccc}
\hline$D$ & $U_{1}$ & $U_{2}$ & \\
\hline$U_{1}$ & 1 & 3 & $U_{3}$ \\
$U_{2}$ & $1 / 3$ & 1 & 2 \\
$U_{3}$ & $1 / 2$ & 2 & $1 / 2$ \\
Single-layer weight & 0.5396 & 0.1634 & 1 \\
Single hierarchy & 1 & 3 & 0.2970 \\
& $\lambda_{\max }=3.0183, \mathrm{CI}=0.0092, \mathrm{RI}=0.5149$, and $\mathrm{CR}=0.0179<0.1$ & 2 \\
\hline
\end{tabular}

TABLE 14: Weights of the evaluation indexes in the index layer.

\begin{tabular}{|c|c|c|c|c|c|c|}
\hline$U_{1}$ & $V_{1}$ & $V_{2}$ & $V_{3}$ & $V_{4}$ & $V_{5}$ & \\
\hline$V_{1}$ & 1 & 2 & 5 & 6 & 7 & \\
\hline$V_{2}$ & $1 / 2$ & 1 & 4 & 5 & 6 & \\
\hline$V_{3}$ & $1 / 5$ & $1 / 4$ & 1 & 2 & 3 & \\
\hline$V_{4}$ & $1 / 6$ & $1 / 5$ & $1 / 2$ & 1 & 2 & $\lambda_{\max }=5.1189$ \\
\hline$V_{5}$ & $1 / 7$ & $1 / 6$ & $1 / 3$ & $1 / 2$ & 1 & $\mathrm{CI}=0.0297$ \\
\hline Single-layer weight & 0.4631 & 0.3129 & 0.1087 & 0.0694 & 0.0459 & $\mathrm{RI}=1.1185$ \\
\hline Single hierarchy & 1 & 2 & 3 & 4 & 5 & $\mathrm{CR}=0.0266<0.1$ \\
\hline$U_{2}$ & $V_{6}$ & & $V_{7}$ & & $V_{8}$ & \\
\hline$V_{6}$ & 1 & & 5 & & 6 & \\
\hline$V_{7}$ & $1 / 5$ & & 1 & & 2 & $\lambda_{\max }=3.0291$ \\
\hline$V_{8}$ & $1 / 6$ & & $1 / 2$ & & 1 & $\mathrm{CI}=0.0146$ \\
\hline Single-layer weight & 0.7258 & & 0.1721 & & 0.1020 & $\mathrm{RI}=0.5149$ \\
\hline Single hierarchy & 1 & & 2 & & 3 & $\mathrm{CR}=0.0282<0.1$ \\
\hline$\overline{U_{3}}$ & \multicolumn{2}{|c|}{$V_{9}$} & \multicolumn{3}{|c|}{$V_{10}$} & \\
\hline$V_{9}$ & \multicolumn{2}{|c|}{1} & \multicolumn{3}{|c|}{2} & $\lambda_{\max }=2.0$ \\
\hline$V_{10}$ & \multicolumn{2}{|c|}{$1 / 2$} & \multicolumn{3}{|c|}{1} & $\mathrm{CI}=0$ \\
\hline Single-layer weight & \multicolumn{2}{|c|}{0.6667} & \multicolumn{3}{|c|}{0.3333} & $\mathrm{RI}=0$ \\
\hline Single hierarchy & \multicolumn{2}{|c|}{1} & \multicolumn{3}{|c|}{2} & $\mathrm{CR}=0<0.1$ \\
\hline
\end{tabular}

TABLE 15: THA of the evaluation indexes.

\begin{tabular}{|c|c|c|c|c|c|}
\hline \multirow{2}{*}{ Evaluation index } & \multicolumn{3}{|c|}{ SHA } & \multicolumn{2}{|c|}{ THA } \\
\hline & $U_{1}$ & $U_{2}$ & $U_{3}$ & Weight & Hierarchy \\
\hline$\overline{V_{1}}$ & 0.4631 & & & 0.250 & 1 \\
\hline$V_{2}$ & 0.3129 & & & 0.169 & 3 \\
\hline$V_{3}$ & 0.1087 & & & 0.059 & 6 \\
\hline$V_{4}$ & 0.0694 & & & 0.037 & 7 \\
\hline$V_{5}$ & 0.0459 & & & 0.025 & 9 \\
\hline$V_{6}$ & & 0.7258 & & 0.119 & 4 \\
\hline$V_{7}$ & & 0.1721 & & 0.028 & 8 \\
\hline$V_{8}$ & & 0.1020 & & 0.017 & 10 \\
\hline$V_{9}$ & & & 0.6667 & 0.198 & 2 \\
\hline \multirow[t]{2}{*}{$V_{10}$} & & & 0.3333 & 0.098 & 5 \\
\hline & & & & \multicolumn{2}{|c|}{$\mathrm{CR}=0.056<0.1$} \\
\hline
\end{tabular}

TABLE 16: Evaluation index values obtained from the test sections.

\begin{tabular}{lcccc}
\hline Evaluation index & Section C-H & \multicolumn{2}{c}{ Section N-Q } & Left line \\
& Left line & Right line & 0.189 & 0.168 \\
$V_{6}(\mathrm{MPa})$ & 0.137 & 0.149 & 221.2 & 141.0 \\
$V_{7}(\mathrm{kPa})$ & 242.2 & 269.9 & 68.64 & 63.55 \\
$V_{8}(\mathrm{~mm})$ & 64.12 & 64.83 & 6 \\
\hline
\end{tabular}


TABLE 17: Location, length, and composition ratio of the composite strata.

\begin{tabular}{|c|c|c|c|c|c|}
\hline $\begin{array}{l}\text { Tunnel } \\
\text { section }\end{array}$ & Location & $\begin{array}{l}\text { Length } \\
(\mathrm{m})\end{array}$ & Rock type & $\begin{array}{l}\text { Maximum thickness } \\
(\mathrm{m})\end{array}$ & $\begin{array}{l}R_{c} \\
(\%) \\
\end{array}$ \\
\hline \multirow{3}{*}{$\mathrm{C}-\mathrm{H}$} & ZCK6 + 600-ZCK6 + 700 & 31.6 & Medium-weathered coarse-grained granite & 5.8 & 83.1 \\
\hline & $\mathrm{ZCK} 8+550-\mathrm{ZCK} 8+650$ & 68.4 & \multirow{2}{*}{$\begin{array}{l}\text { Medium- to microweathered coarse-grained } \\
\text { granite }\end{array}$} & 5.2 & 74.5 \\
\hline & YCK7 + 680-YCK7 + 750 & 52.3 & & 4.9 & 70.2 \\
\hline \multirow{4}{*}{ N-Q } & ZCK16+550-ZCK16 + 650 & 89.9 & \multirow{4}{*}{$\begin{array}{l}\text { Medium- to microweathered coarse-grained } \\
\text { granite }\end{array}$} & 3.2 & 45.8 \\
\hline & $\mathrm{ZCK} 17+850-\mathrm{ZCK} 17+900$ & 16.6 & & 4.6 & 65.9 \\
\hline & YCK $15+550-$ YCK $15+850$ & 133.6 & & 5.8 & 83.1 \\
\hline & YCK16 + 100-YCK16 + 250 & 82.3 & & 6.2 & 88.8 \\
\hline
\end{tabular}

TABLE 18: Assigned values of the evaluation indexes for assessing the tunnelling adaptability of an EPB TBM.

\begin{tabular}{|c|c|c|c|c|c|}
\hline \multirow{2}{*}{$\begin{array}{l}\text { Evaluation } \\
\text { index }\end{array}$} & \multirow[b]{2}{*}{ Unit } & \multicolumn{2}{|c|}{ Section C-H } & \multicolumn{2}{|c|}{ Section N-Q } \\
\hline & & $\begin{array}{l}\text { Left } \\
\text { line }\end{array}$ & $\begin{array}{l}\text { Right } \\
\text { line }\end{array}$ & $\begin{array}{l}\text { Left } \\
\text { line }\end{array}$ & $\begin{array}{l}\text { Right } \\
\text { line }\end{array}$ \\
\hline$V_{1}$ & $\mathrm{kN}$ & \multicolumn{4}{|c|}{49,588} \\
\hline$V_{2}$ & $\mathrm{kN} \cdot \mathrm{m}$ & \multicolumn{4}{|c|}{7,806} \\
\hline$V_{3}$ & $\%$ & \multicolumn{4}{|c|}{33} \\
\hline$V_{4}$ & $\mathrm{~m}^{3} / \mathrm{h}$ & \multicolumn{4}{|c|}{440} \\
\hline$V_{5}$ & $\mathrm{~mm}$ & \multicolumn{4}{|c|}{90} \\
\hline$V_{6}$ & $\mathrm{MPa}$ & 0.137 & 0.137 & 0.137 & 0.137 \\
\hline$V_{7}$ & $\mathrm{kPa}$ & 242.2 & 269.9 & 221.2 & 141.0 \\
\hline$V_{8}$ & $\mathrm{~mm}$ & 64.12 & 64.83 & 68.64 & 63.55 \\
\hline$V_{9}$ & $\%$ & 77.2 & 70.2 & 48.9 & 85.3 \\
\hline$V_{10}$ & $\mathrm{~m}$ & 0 & 1.2 & 0 & 0 \\
\hline
\end{tabular}

TABLE 19: Evaluated degrees of tunnelling adaptability of the EPB TBM.

\begin{tabular}{lcccc}
\hline Tunnel section & \multicolumn{2}{c}{ Section C-H } & \multicolumn{2}{c}{ Section N-Q } \\
Left line & $\begin{array}{c}\text { Right } \\
\text { line }\end{array}$ & Left line & $\begin{array}{c}\text { Right } \\
\text { line }\end{array}$ \\
\hline $\begin{array}{l}\text { Degree of adaptability } \\
D\end{array}$ & 0.9135 & 0.8332 & 0.7621 & 0.9556 \\
Adaptability grade & I & II & II & I \\
\hline
\end{tabular}

$$
R=\left[\begin{array}{cccc}
1 & 1 & 1 & 1 \\
1 & 1 & 1 & 1 \\
1 & 1 & 1 & 1 \\
1 & 1 & 1 & 1 \\
0.5 & 0.5 & 0.5 & 0.5 \\
0.6024 & 0.7470 & 1 & 0.9759 \\
0.0671 & 0.1111 & 0.0337 & 0 \\
0.9749 & 0.9951 & 1 & 0.9586 \\
1 & 1 & 0 & 1 \\
1 & 0 & 1 & 1
\end{array}\right] .
$$

The adaptability degree of $\mathbf{O}$ is obtained by substituting $\bar{V}$ and $\mathbf{R}$ into equation (9):

$D=\bar{V} \times R=\left[\begin{array}{llll}0.9135 & 0.8832 & 0.7621 & 0.9556\end{array}\right]$

Based on the adaptability classification in Table 3, the adaptability grades of EPB TBM tunnelling in Section C-H and Section N-Q are given in Table 19. That means this type of EPB TBM is adaptable to tunnelling through highly variable composite strata. The presence of large spherical weathered boulders along the right line of Section $\mathrm{C}-\mathrm{H}$ and the left line of Section N-Q leads to a lower adaptability grade, which was confirmed by the actual excavation. Overall, the actual excavation of two sections showed that the proposed method for evaluating tunnelling adaptability of EPB TBM is correct and reasonable.

\section{Conclusions}

The method for evaluating EPB TBM tunnelling adaptability to tunnel excavation is required for choosing the suitable technical parameters of the machine and to minimize the risks of tunnelling under adverse geological conditions. The evaluation is generally difficult because of the differing effects and complex relationships among the various factors involved. In the present study, a quantitative method based on AHP and fuzzy comprehensive evaluation was developed for the evaluation of EPB TBM adaptability under complex geological conditions. The rationality of the proposed method was verified by an actual tunnel construction project. The following is a summary of the proposed method and the conclusions drawn from the study:

(1) The first step in the evaluation of EPB TBM tunnelling adaptability is the enumeration of various potential influencing factors and pairwise comparisons of their impacts. The bases of the comparison include construction experience, findings of scientific research, and expert opinion. This is used as a foundation for the application of AHP to determine the impact weights of various factors. The weights are then used to hierarchically arrange the selected evaluation indexes. An understanding of the effects of the factors would directly impact the quality of the selected evaluation indexes.

(2) For the establishment of the EIS of the tunnelling adaptability of an EPB TBM in this study, (i) the tunnelling adaptability of the EPB TBMs applied to the composite strata encountered during the construction of the Shenzhen Metro Line 11 was used as the target layer; (ii) the EPB TBM design, tunnel construction plan, and geological conditions were used as the criteria layer; and (iii) the total thrust, cutterhead torque, cutterhead opening ratio, muck amount of the screw conveyor, cutter spacing, earth pressure in the cutterhead chamber, wall-back grouting pressure, shield tail void, composite strata, and spherical weathered boulders were used as the 
index layer. The rational EIS was the foundation on which the evaluation targets were determined.

(3) The corresponding FMFs were established based on the effects of 10 selected evaluation indexes on the tunnelling adaptability of the EPB TBMs. Each FMF prescribed the value range of the related evaluation index. Based on the proposed FMFs, the fuzzy mathematical method was used to ensure the generality of the various evaluation indexes. The validity of the FMFs was dependent on the ability to quantitatively define the effects of the influencing factors.

(4) After the establishment of the EIS, values were assigned to different evaluation indexes using technical and geotechnical data obtained from the Shenzhen Metro Line 11 project. Fuzzy comprehensive evaluation was then used to evaluate the tunnelling adaptability of the EPB TBMs used for the tunnel excavation. The evaluation results were found to be consistent with the observations made from actual shield tunnelling.

(5) The present study was based on the current understanding of the considered influencing factors. It should be noted that there are a few other important factors that were not taken into account owing to the difficulty of quantifying them. Further study is required to consider such factors to improve the accuracy of the proposed EPB TBM tunnelling adaptability evaluation method.

\section{Data Availability}

The raw/processed data required to reproduce these findings cannot be shared at this time as the data also form part of an ongoing study.

\section{Conflicts of Interest}

The authors declare that they have no conflicts of interest.

\section{Acknowledgments}

The authors are grateful for the additional support of the China Railway Construction and Investment Group Co., Ltd. in Shenzhen. This study was supported by the National Key Basic Research Program of China (Grant no. 2014CB046906).

\section{References}

[1] W. B. Zhu and S. J. Ju, Construction Technology of Shield Machine in Mixed Ground, China Science Publishing and Media Ltd., Peking, China, 2006, in Chinese.

[2] H. Y. Liao, Technology for Shield Tunnel in Mixed Face Ground Conditions-Study \& Practice in Shield Tunnelling Projects of Guangzhou Metro, China Architecture and Building Press, Peking, China, 2012, in Chinese.

[3] Z. C. Ding, Z. Y. Zhang, and Y. Bai, "Application of shield selection and shield improvement in Guangzhou metro shield tunnel construction," Chinese Journal of Rock Mechanics and Engineering, vol. 21, no. 12, pp. 1820-1823, 2002, in Chinese.

[4] H. Z. Zhang, "Practice for the type-selection of TBM and the operative feature of Wirth," Journal of Railway Engineering Society, vol. 3, pp. 37-41, 2004, in Chinese.

[5] J. G. Liu, Study and Practice of Shield Tunnelling Technology in Shenzhen Metro, China Communications Press, Peking, China, (in Chinese), 2011.

[6] J. Zhao, Q. M. Gong, and Z. Eisensten, "Tunnelling through a frequently changing and mixed ground: a case history in Singapore," Tunnelling and Underground Space Technology, vol. 22, no. 4, pp. 388-400, 2007.

[7] N. Tokgöz, I. Serkan Binen, and E. Avunduk, "An evaluation of fine grained sedimentary materials in terms of geotechnical parameters which define and control excavation performance of EPB TBM's," Tunnelling and Underground Space Technology, vol. 47, pp. 211-221, 2015.

[8] Q. F. Hu, H. W. Huang, and Y. R. Yan, "Risk analysis for cutter head failure of composite EPB shield based on fuzzy fault tree," in Proceedings of the 6th International Symposium (IS-SHANGHAI 2008), pp. 10-12, Shanghai, China, April 2008.

[9] K.-C. Hyun, S. Min, H. Choi, J. Park, and I.-M. Lee, "Risk analysis using fault-tree analysis (FTA) and analytic hierarchy process (AHP) applicable to shield TBM tunnels," Tunnelling and Underground Space Technology, vol. 49, pp. 121-129, 2015.

[10] E.-S. Hong, I.-M. Lee, H.-S. Shin, S.-W. Nam, and J.-S. Kong, "Quantitative risk evaluation based on event tree analysis technique: application to the design of shield TBM," Tunnelling and Underground Space Technology, vol. 24, no. 3, pp. 269-277, 2009.

[11] M. Sapigni, M. Berti, E. Bethaz, A. Busillo, and G. Cardone, "TBM performance estimation using rock mass classifications," International Journal of Rock Mechanics and Mining Sciences, vol. 39, no. 6, pp. 771-788, 2002.

[12] T. Yan, S.-L. Shen, A. Zhou, and H.-M. Lyu, "Construction efficiency of shield tunnelling through soft deposit in Tianjin, China," Tunnelling and Underground Space Technology, vol. 112, Article ID 103917, 2021.

[13] R. Mikaeil, M. Z. Naghadehi, and F. Sereshki, "Multifactorial fuzzy approach to the penetrability classification of TBM in hard rock conditions," Tunnelling and Underground Space Technology, vol. 24, no. 5, pp. 500-505, 2009.

[14] S.-S. Lin, S.-L. Shen, A. Zhou, and Y.-S. Xu, "Novel model for risk identification during karst excavation," Reliability Engineering and System Safety, vol. 209, Article ID 107435, 2021.

[15] J.-P. Dudt and A. Delisio, "The "penalty factors" method for the prediction of TBM performances in changing grounds," Tunnelling and Underground Space Technology, vol. 57, pp. 195-200, 2016.

[16] M. Alvarez Grima, P. A. Bruines, and P. N. W. Verhoef, "Modeling tunnel boring machine performance by neurofuzzy methods," Tunnelling and Underground Space Technology, vol. 15, no. 3, pp. 259-269, 2000.

[17] O. Acaroglu, L. Ozdemir, and B. Asbury, "A fuzzy logic model to predict specific energy requirement for TBM performance prediction," Tunnelling and Underground Space Technology, vol. 23, no. 5, pp. 600-608, 2008.

[18] O. Acaroglu, "Prediction of thrust and torque requirements of TBMs with fuzzy logic models," Tunnelling and Underground Space Technology, vol. 26, no. 2, pp. 267-275, 2011.

[19] H.-M. Lyu, W.-J. Sun, S.-L. Shen, and A.-N. Zhou, "Risk assessment using a new consulting process in fuzzy AHP," 
Journal of Construction Engineering and Management, vol. 146, no. 3, Article ID 04019112, 2020.

[20] J. Rostami, "Performance prediction of hard rock Tunnel Boring Machines (TBMs) in difficult ground," Tunnelling and Underground Space Technology, vol. 57, pp. 173-182, 2016.

[21] A. G. Benardos and D. C. Kaliampakos, "A methodology for assessing geotechnical hazards for TBM tunnelling-illustrated by the Athens Metro, Greece," International Journal of Rock Mechanics and Mining Sciences, vol. 41, no. 6, pp. 987-999, 2004.

[22] E. Farrokh and J. Rostami, "Effect of adverse geological condition on TBM operation in Ghomroud tunnel conveyance project," Tunnelling and Underground Space Technology, vol. 24, no. 4, pp. 436-446, 2009.

[23] Q. Gong, L. Yin, H. Ma, and J. Zhao, "TBM tunnelling under adverse geological conditions: an overview," Tunnelling and Underground Space Technology, vol. 57, pp. 4-17, 2016.

[24] A. Yazdani-Chamzini and S. H. Yakhchali, "Tunnel Boring Machine (TBM) selection using fuzzy multicriteria decision making methods," Tunnelling and Underground Space Technology, vol. 30, pp. 194-204, 2012.

[25] J. K. Hamidi, K. Shahriar, B. Rezai et al., "Risk assessment based selection of rock TBM for adverse geological conditions using Fuzzy-AHP," Bulletin of Engineering Geology and the Environment, vol. 69, no. 5, pp. 523-532, 2010.

[26] K. Shahriar, M. Sharifzadeh, and J. K. Hamidi, "Geotechnical risk Assessment based approach for rock TBM selection in difficult ground conditions," Tunnelling and Underground Space Technology, vol. 23, no. 3, pp. 318-325, 2008.

[27] A. A. Shaheen, A. R. Fayek, and S. M. AbouRizk, "Methodology for integrating fuzzy expert systems and discrete event simulation in construction engineering," Canadian Journal of Civil Engineering, vol. 36, no. 9, pp. 1478-1490, 2009.

[28] S. Okubo, K. Fukui, and W. Chen, "Expert system for applicability of tunnel boring machines in Japan," Rock Mechanics and Rock Engineering, vol. 36, no. 4, pp. 305-322, 2003.

[29] A. Salimi, J. Rostami, C. Moormann, and A. Delisio, “Application of non-linear regression analysis and artificial intelligence algorithms for performance prediction of hard rock TBMs," Tunnelling and Underground Space Technology, vol. 58, pp. 236-246, 2016.

[30] K. Elbaz, S. L. Shen, A. N. Zhou et al., "Prediction of disc cutter life during shield tunneling with AI via the incorporation of a genetic algorithm into a GMDH-type neural network," Engineering, vol. 7, pp. 238-251, 2021.

[31] S.-S. Lin, S.-L. Shen, N. Zhang, and A. Zhou, "Modelling the performance of EPB shield tunnelling using machine and deep learning algorithms," Geoscience Frontiers, vol. 12, no. 5, Article ID 101177, 2021.

[32] N. Zhang, S.-L. Shen, A. Zhou, and Y.-F. Jin, "Application of LSTM approach for modelling stress-strain behaviour of soil," Applied Soft Computing, vol. 100, Article ID 106959, 2021.

[33] B. Bai, D. Rao, T. Xu, and P. Chen, "SPH-FDM boundary for the analysis of thermal process in homogeneous media with a discontinuous interface," International Journal of Heat and Mass Transfer, vol. 117, pp. 517-526, 2018.

[34] B. Bai and X. Shi, "Experimental study on the consolidation of saturated silty clay subjected to cyclic thermal loading," Geomechanics and Engineering, vol. 12, no. 4, pp. 707-721, 2017.
[35] T. L. Saaty, "A scaling method for priorities in hierarchical structures," Journal of Mathematical Psychology, vol. 15, no. 3, pp. 234-281, 1977.

[36] T. L. Saaty, The Analytic Hierarchy Process, McGraw-Hill, New York, NY, USA, 1980.

[37] Japan Society of Civil Engineering (JSCE), W. zhu, Tunnel Standards and Codes - Shield Tunnel and Explanation, China Architecture \& Building Press, Peking, China, 2006, in Chinese.

[38] S. Z. Chen and K. R. Hong, An Introduction to Design of Shield Machine in Mixed Ground, China Communication Press, Peking, China, 2010. 